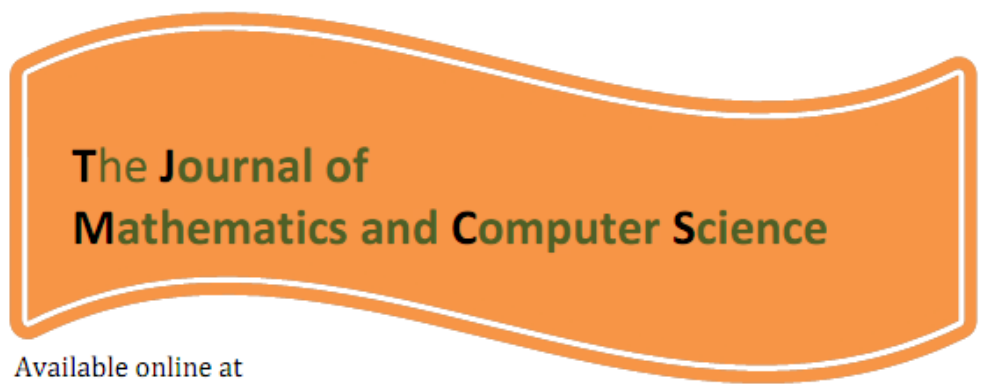

http://www.TJMCS.com

The Journal of Mathematics and Computer Science Vol .3 No.2 (2011) 246 - 261

\title{
A remark on the coupled fixed point theorems for mixed monotone operators in partially ordered metric spaces
}

\author{
S.H. Rasouli ${ }^{a}$, M. Bahrampour ${ }^{b}$ \\ ${ }^{a}$ Department of Mathematics, Faculty of Basic Science, \\ Babol University of Technology, Babol, Iran \\ e-mail: s.h.rasouli@nit.ac.ir \\ ${ }^{b}$ Department of Mathematics, \\ Islamic Azad University Ghaemshahr branch, Iran \\ e-mail: md.bahrampour@gmail.com
}

\begin{abstract}
We present a coupled fixed point theorems for mixed monotone operators in partially ordered metric spaces.
\end{abstract}

Keywords: Coupled fixed point; Partially ordered set; Mixed monotone operators. AMS Subject Classification: 47H10

\section{Introduction}

Mixed monotone operators were introduced by D.Guo and V.Lakshmikantham in 1987[3]. Existence of fixed point in partially ordered set has been considered recently in [1-19]. The 
purpose of this paper is to present some coupled fixed point theorems for mixed monotone operator in the context of ordered metric spaces involving following functions with the method of $[2]$.

Let $\delta$ denote the class of those functions $\beta:[0, \infty) \rightarrow[0, \infty)$ which satisfies the condition $\beta\left(t_{n}\right) \longrightarrow 1$ implies $t_{n} \rightarrow 0$.

Now we briefly recall various basic definition and facts.

Let $(X, \leq)$ be a partially ordered set and $F: X \times X \rightarrow X$. we say that $\mathrm{F}$ has the mixed monotone property if $F(x, y)$ is monotone nondecreasing in $x$ and is monotone nonincreasing in $y$, that is , for any $x, y \in X$,

$$
x_{1}, x_{2} \in X, \quad x_{1} \leq x_{2} \Rightarrow F\left(x_{1}, y\right) \leq F\left(x_{2}, y\right)
$$

and

$$
y_{1}, y_{2} \in X, \quad y_{1} \leq y_{2} \Rightarrow F\left(x, y_{1}\right) \geq F\left(x, y_{2}\right)
$$

An element $(x, y) \in X \times X$ is said to be a coupled fixed point of the mapping $F$ if

$$
F(x, y)=x \quad \text { and } \quad F(y, x)=y
$$

Theorem 1. ([1]) Let $(X, \leq)$ be a partially ordered set and suppose that there exists a metric $\mathrm{d}$ in $\mathrm{X}$ such that $(X, d)$ is a complete metric space.Let $f: X \rightarrow X$ be an increasing mapping such that there exists an element $x_{0} \in X$ with $x_{0} \leq f\left(x_{0}\right)$. suppose that there exists $\beta \in \delta$ such that

$$
d(f(x), f(y)) \leq \beta(d(x, y)) d(x, y) \text {, for each } x, y \in X, \text { with } x \geq y \text {. }
$$

Assume that either $\mathrm{f}$ is continuous or $\mathrm{X}$ is such that 
if an increasing sequence $\left\{x_{n}\right\} \rightarrow x$ in $X$, then $x_{n} \leq x, \forall n$.

Besides, if

for each $x, y \in X$ there exists $z \in M$ which is comparable to $x$ and $y$.

Then $f$ has a unique fixed point.

Bhaskar and Lakshmikantham [3] introduced the notions of mixed monotone mapping and a coupled fixed point.

Theorem 2. $([3])$ Let $(X, \leq)$ be a partially ordered set and suppose that there exists a metric $\mathrm{d}$ in $\mathrm{X}$ such that $(X, d)$ is a complete metric space.Let $F: X \times X \rightarrow X$ be a mapping having the mixed monotone property on $X$ and assume that there exists $k \in[0,1)$ with

$$
d(F(x, y), F(u, v)) \leq \frac{k}{2}[d(x, u), d(y, v)], \text { for any } x \geq u \text { and } y \leq v
$$

If there exist $x_{0}, y_{0} \in X$ such that

$$
x_{0} \leq F\left(x_{0}, y_{0}\right) \quad \text { and } \quad y_{0} \geq F\left(y_{0}, x_{0}\right)
$$

and suppose either $F$ us continuous or $X$ satisfies the following property:

if $\left(x_{n}\right)$ is a nondecreasing sequence with $x_{n} \rightarrow x$ then $x_{n} \leq x$ for each $n \in N$

and

if $\left(y_{n}\right)$ is a nonincreasing sequence with $y_{n} \rightarrow y$ then $y \leq y_{n}$ for each $n \in N$

then $F$ has a coupled fixed point. 


\section{Main result}

let $(X, \leq)$ be a partially ordered set and $d$ a metric on $X$ such that $(X, d)$ is a complete metric space.Further, we consider in the product space $X \times X$ the following partial order:

$$
\text { if }(x, y),(u, v) \in X \times X,(x, y) \leq(u, v) \Longleftrightarrow x \leq u \quad \text { and } \quad y \geq v \text {. }
$$

Now we present the following theorem which is a version of Theorem2.1 of [1] in the context of mapping with the mixed monotone property.

Theorem 3.Let $(X, \leq)$ be a partially ordered set and suppose that there exists a metric $\mathrm{d}$ in $\mathrm{X}$ such that $(X, d)$ is a complete metric space.Let $F: X \times X \rightarrow X$ be a mapping having the mixed monotone property on $\mathrm{X}$ and continuous such that

$$
d(F(x, y), F(u, v)) \leq \beta(\max (d(x, u), d(y, v))) \max (d(x, u), d(y, v)),
$$

for all $x, y, u, v \in X$ with $x \geq u$ and $y \leq v$, where $\beta \in \delta$.

If there exist $x_{0}, y_{0} \in X$ with

$$
x_{0} \leq F\left(x_{0}, y_{0}\right) \quad \text { and } \quad y_{0} \geq F\left(y_{0}, x_{0}\right)
$$

then $F$ has a coupled fixed point.

Proof.We construct sequences $\left(x_{n}\right)$ and $\left(y_{n}\right)$ putting

$$
x_{n+1}=F\left(x_{n}, y_{n}\right) \quad \text { and } \quad y_{n+1}=F\left(y_{n}, x_{n}\right) \text {, for } n \geq 0 .
$$

In order to the proof is more comprehensive we will divide it in several steps.

Step $1 x_{n} \leq x_{n+1}$ and $y_{n} \geq y_{n+1}$, for $n \geq 0$.

In fact, we use the mathematical induction. 
As $x_{0} \leq F\left(x_{0}, y_{0}\right)=x_{1}$ and $y_{0} \geq F\left(y_{0}, x_{0}\right)=y_{1}$ our claim is satisfied for $n=0$.

Suppose that our claim holds for some fixed $n>0$.Then, since $x_{n-1} \leq x_{n}$ and $y_{n} \leq y_{n-1}$ and, as $F$ has the mixed monotone property, we get

$$
x_{n+1}=F\left(x_{n}, y_{n}\right) \geq F\left(x_{n-1}, y_{n}\right) \geq F\left(x_{n-1}, y_{n-1}\right)=x_{n}
$$

and

$$
y_{n+1}=F\left(y_{n}, x_{n}\right) \leq F\left(y_{n-1}, x_{n}\right) \leq F\left(y_{n-1}, x_{n-1}\right)=y_{n}
$$

and this proves our claim.

Step $2 \lim _{n \rightarrow \infty} d\left(x_{n}, x_{n+1}\right)=\lim _{n \rightarrow \infty} d\left(y_{n}, y_{n+1}\right)=0$.

In facet, using the contractive condition and, since $x_{n} \geq x_{n-1}$ and $y_{n} \leq y_{n-1}$ (step1), we obtain

$$
\begin{aligned}
d\left(x_{n+1}, x_{n}\right) & =d\left(F\left(x_{n}, y_{n}\right), F\left(x_{n-1}, y_{n-1}\right)\right) \\
& \leq \beta\left(\max \left(d\left(x_{n}, x_{n-1}\right), d\left(y_{n}, y_{n-1}\right)\right)\right) \max \left(d\left(x_{n}, x_{n-1}\right), d\left(y_{n}, y_{n-1}\right)\right) \\
& \leq \max \left(d\left(x_{n}, x_{n-1}\right), d\left(y_{n}, y_{n-1}\right)\right)
\end{aligned}
$$

and consequently

$$
d\left(x_{n+1}, x_{n}\right) \leq \max \left(d\left(x_{n}, x_{n-1}\right), d\left(y_{n}, y_{n-1}\right)\right)
$$

Similarly, since $x_{n-1} \leq x_{n}$ and $y_{n-1} \geq y_{n}$, we get

$$
\begin{aligned}
d\left(y_{n+1}, y_{n}\right) & =d\left(F\left(y_{n}, x_{n}\right), F\left(y_{n-1}, x_{n-1}\right)\right) \\
& \leq \beta\left(\max \left(d\left(y_{n-1}, y_{n}\right), d\left(x_{n-1}, x_{n}\right)\right)\right) \max \left(d\left(y_{n-1}, y_{n}\right), d\left(x_{n-1}, x_{n}\right)\right) \\
& \leq \max \left(d\left(x_{n}, x_{n-1}\right), d\left(y_{n}, y_{n-1}\right)\right)
\end{aligned}
$$


and, consequently,

$$
d\left(y_{n+1}, y_{n}\right) \leq \max \left(d\left(x_{n}, x_{n-1}\right), d\left(y_{n}, y_{n-1}\right)\right)
$$

By (2) and (4)

$$
\max \left(d\left(x_{n+1}, x_{n}\right), d\left(y_{n+1}, y_{n}\right)\right) \leq \max \left(d\left(x_{n}, x_{n-1}\right), d\left(y_{n}, y_{n-1}\right)\right)
$$

and, thus, the sequence $\left(\max \left(d\left(x_{n+1}, x_{n}\right), d\left(y_{n+1}, y_{n}\right)\right)\right)$ is nonnegative decreasing. This implies that there exists $r \geq 0$ such that

$$
\lim _{n \rightarrow \infty} \max \left(d\left(x_{n+1}, x_{n}\right), d\left(y_{n+1}, y_{n}\right)\right)=r
$$

assume that $r>0$ taking account this and (1) and (3) we get

$\max \left(d\left(x_{n+1}, x_{n}\right), d\left(y_{n+1}, y_{n}\right)\right) \leq \beta\left(\max \left(d\left(x_{n}, x_{n-1}\right), d\left(y_{n}, y_{n-1}\right)\right)\right) \max \left(d\left(x_{n}, x_{n-1}\right), d\left(y_{n}, y_{n-1}\right)\right)$

then we have

$$
\frac{\max \left(d\left(x_{n+1}, x_{n}\right), d\left(y_{n+1}, y_{n}\right)\right)}{\max \left(d\left(x_{n}, x_{n-1}\right), d\left(y_{n}, y_{n-1}\right)\right)} \leq \beta\left(\max \left(d\left(x_{n}, x_{n-1}\right), d\left(y_{n}, y_{n-1}\right)\right)\right)
$$

Letting $n \rightarrow \infty$ in the last inequality and taking into account (5), we get

$$
\lim _{n \rightarrow \infty} \beta\left(\max \left(d\left(x_{n}, x_{n-1}\right), d\left(y_{n}, y_{n-1}\right)\right)\right)=1
$$

and since $\beta \in \delta$ this implies $r=0$. and, consequently,

$$
\lim _{n \rightarrow \infty}\left(\max \left(d\left(x_{n+1}, x_{n}\right), d\left(y_{n+1}, y_{n}\right)\right)\right)=0 .
$$


This proves our claim.

Step $3\left(x_{n}\right),\left(y_{n}\right)$ are Cauchy sequence.

In fact, assume that at least one of the sequence $\left(x_{n}\right)$ or $\left(y_{n}\right)$ is not a Cauchy sequence. This implies that $\lim _{n, m \rightarrow \infty} d\left(x_{n}, x_{m}\right) \nrightarrow \rightarrow 0$ or $\lim _{n, m \rightarrow \infty} d\left(y_{n}, y_{m}\right) \nrightarrow \rightarrow 0$, and, consequently,

$$
\lim _{n, m \rightarrow \infty}\left(\max \left(d\left(x_{n}, x_{m}\right), d\left(y_{n}, y_{m}\right)\right)\right) \not \rightarrow 0
$$

This means that there exist $\epsilon>0$ for which we can find subsequences $\left(x_{m(k)}\right)$ and $\left(x_{n(k)}\right)$ with $n(k)>m(k)>k$ such that

$$
\lim _{n, m \rightarrow \infty}\left(\max \left(d\left(x_{m(k)}, x_{n(k)}\right), d\left(y_{m(k)}, y_{n(k)}\right)\right)\right) \geq \epsilon
$$

Further, corresponding to $m(k)$ we can choose $n(k)$ in such way that it is the smallest integer with $n(k)>m(k)$ and satisfying (6).

Then

$$
\left(\max \left(d\left(x_{m(k)}, x_{n(k)-1}\right), d\left(y_{m(k)}, y_{n(k)-1}\right)\right)\right)<\epsilon
$$

Since $x_{n(k)-1} \geq x_{m(k)-1}$ and $y_{n(k)-1} \leq y_{m(k)-1}$, using the contractive condition we can obtain

$$
\begin{aligned}
d\left(x_{n(k)}, x_{m(k)}\right) & =d\left(F\left(\left(x_{n(k)-1}, y_{n(k)-1}\right)\right), F\left(\left(x_{m(k)-1}, y_{m(k)-1}\right)\right)\right) \\
\leq & \beta\left(\max \left(d\left(x_{n(k)-1}, x_{m(k)-1}\right), d\left(y_{n(k)-1}, y_{m(k)-1}\right)\right)\right) \\
& \times \max \left(d\left(x_{n(k)-1}, x_{m(k)-1}\right), d\left(y_{n(k)-1}, y_{m(k)-1}\right)\right)
\end{aligned}
$$

and

$$
\begin{aligned}
d\left(y_{n(k)}, y_{m(k)}\right) & =d\left(F\left(\left(y_{n(k)-1}, x_{n(k)-1}\right)\right), F\left(\left(y_{m(k)-1}, x_{m(k)-1}\right)\right)\right) \\
& =d\left(F\left(\left(y_{m(k)-1}, x_{m(k)-1}\right)\right)\right), F\left(\left(y_{n(k)-1}, x_{n(k)}-1\right)\right) \\
& \leq \beta\left(\max \left(d\left(x_{n(k)-1}, x_{m(k)-1}\right), d\left(y_{n(k)-1}, y_{m(k)-1}\right)\right)\right) \\
& \times \max \left(d\left(x_{n(k)-1}, x_{m(k)-1}\right), d\left(y_{n(k)-1}, y_{m(k)-1}\right)\right) .
\end{aligned}
$$


By (8) and (9) we get

$$
\begin{aligned}
& \max \left(d\left(x_{n(k)}, x_{m(k)}\right), d\left(y_{n(k)}, y_{m(k)}\right)\right) \\
\leq & \beta\left(\max \left(d\left(x_{n(k)-1}, x_{m(k)-1}\right), d\left(y_{n(k)-1}, y_{m(k)-1}\right)\right)\right) \max \left(d\left(x_{n(k)-1}, x_{m(k)-1}\right), d\left(y_{n(k)-1}, y_{m(k)-1}\right)\right) .
\end{aligned}
$$

On the other hand, the triangle inequality and (7) gives us

$$
d\left(x_{n(k)}, x_{m(k)}\right) \leq d\left(x_{n(k)}, x_{n(k)-1}\right)+d\left(x_{m(k)-1}, x_{m(k)}\right)<d\left(x_{n(k)}, x_{n(k)-1}\right)+\epsilon
$$

and

$$
d\left(y_{n(k)}, y_{m(k)}\right) \leq d\left(y_{n(k)}, y_{n(k)-1}\right)+d\left(y_{m(k)-1}, y_{m(k)}\right)<d\left(y_{n(k)}, y_{n(k)-1}\right)+\epsilon
$$

From (6),(11) and (12) we get

$$
\epsilon \leq \max \left(d\left(x_{n(k)}, x_{m(k)}\right), d\left(y_{n(k)}, y_{m(k)}\right)\right) \leq \max \left(d\left(x_{n(k)}, x_{n(k)-1}\right), d\left(y_{n(k)}, y_{n(k)-1}\right)\right)+\epsilon
$$

Letting $k \rightarrow \infty$ in the last inequality and taking into account the step 2 we have

$$
\lim _{k \rightarrow \infty} \max \left(d\left(x_{n(k)}, x_{m(k)}\right), d\left(y_{n(k)}, y_{m(k)}\right)\right)=\epsilon
$$

Again, the triangle inequality and (7) gives us

$$
d\left(x_{n(k)-1}, x_{m(k)-1}\right) \leq d\left(x_{n(k)-1}, x_{m(k)}\right)+d\left(x_{m(k)}, x_{m(k)-1}\right)<\epsilon+d\left(x_{m(k)}, x_{m(k)-1}\right)
$$

and

$$
d\left(y_{n(k)-1}, y_{m(k)-1}\right) \leq d\left(y_{n(k)-1}, y_{m(k)}\right)+d\left(y_{m(k)}, y_{m(k)-1}\right)<\epsilon+d\left(y_{m(k)}, y_{m(k)-1}\right)
$$


By (14) and (15) we obtain

$$
\begin{aligned}
& \max \left(d\left(x_{n(k)-1}, x_{m(k)-1}\right), d\left(y_{n(k)-1}, y_{m(k)-1}\right)\right) \\
\leq & \max \left(d\left(x_{m(k)}, x_{m(k)-1}\right), d\left(y_{m(k)}, y_{m(k)-1}\right)\right)+\epsilon
\end{aligned}
$$

Using the triangle inequality we have

$$
d\left(x_{n(k)}, x_{m(k)}\right) \leq d\left(x_{n(k)}, x_{n(k)-1}\right)+d\left(x_{n(k)-1}, x_{m(k)-1}\right)+d\left(x_{m(k)-1}, x_{m(k)}\right)
$$

and

$$
d\left(y_{n(k)}, y_{m(k)}\right) \leq d\left(y_{n(k)}, y_{n(k)-1}\right)+d\left(y_{n(k)-1}, y_{m(k)-1}\right)+d\left(y_{m(k)-1}, y_{m(k)}\right)
$$

and by the last inequality and (6) we get

$$
\begin{aligned}
\epsilon & \leq \max \left(d\left(x_{n(k)}, x_{m(k)}\right), d\left(y_{n(k)}, y_{m(k)}\right)\right) \\
& \leq \max \left(d\left(x_{n(k)}, x_{n(k)-1}\right), d\left(y_{n(k)}, y_{n(k)-1}\right)\right) \\
& +\max \left(d\left(x_{n(k)-1}, x_{m(k)-1}\right), d\left(y_{n(k)-1}, y_{m(k)-1}\right)\right) \\
& +\max \left(d\left(x_{m(k)-1}, x_{m(k)}\right), d\left(y_{m(k)-1}, y_{m(k)}\right)\right)
\end{aligned}
$$

By (16) and (17) we have

$$
\begin{gathered}
\epsilon-\max \left(d\left(x_{n(k)}, x_{n(k)-1}\right), d\left(y_{n(k)}, y_{n(k)-1}\right)\right)-\max \left(d\left(x_{m(k)-1}, x_{m(k)}\right), d\left(y_{m(k)-1}, y_{m(k)}\right)\right) \\
\leq \max \left(d\left(x_{n(k)-1}, x_{m(k)-1}\right), d\left(y_{n(k)-1}, y_{m(k)-1}\right)\right)<\max \left(d\left(x_{m(k)}, x_{m(k)-1}\right), d\left(y_{m(k)}, y_{m(k)-1}\right)\right)+\epsilon
\end{gathered}
$$

Letting $k \rightarrow \infty$ in the last inequality and using step 2 we obtain

$$
\lim _{k \rightarrow \infty} \max \left(d\left(x_{n(k)-1}, x_{m(k)-1}\right), d\left(y_{n(k)-1}, y_{m(k)-1}\right)\right)=\epsilon
$$


Finally, letting $k \rightarrow \infty$ in (10) and using (13),(18) we get

$$
\epsilon \leq \beta\left(\max \left(d\left(x_{n(k)-1}, x_{m(k)-1}\right), d\left(y_{n(k)-1}, y_{m(k)-1}\right)\right)\right) \epsilon \quad \text { or } \quad \varepsilon \leq \beta(\epsilon) \epsilon .
$$

we obtain $\lim _{n, m \rightarrow \infty} \beta\left(\max \left(d\left(x_{n}, x_{m}\right), d\left(y_{n}, y_{m}\right)\right)\right)=1$.

But since $\beta \in \delta$, we get $\lim _{n, m \rightarrow \infty} \max \left(d\left(x_{n}, x_{m}\right), d\left(y_{n}, y_{m}\right)\right)=0$. This is a contradiction. This proves our claim.

Since $(X, d)$ is a complete metric there exist $x, y \in X$ such that

$$
\lim _{n \rightarrow \infty} x_{n}=x \text { and } \quad \lim _{n \rightarrow \infty} y_{n}=y
$$

Now we prove that $(x, y)$ is a couple fixed point of $F$.

In fact, as $x_{n+1}=F\left(x_{n}, y_{n}\right)$ and $y_{n+1}=F\left(y_{n}, x_{n}\right)$ and using continuity of $F$ and (19) we have

$$
\begin{aligned}
& x=\lim _{n \rightarrow \infty} F\left(x_{n}, y_{n}\right)=F\left(\lim _{n \rightarrow \infty} x_{n}, \lim _{n \rightarrow \infty} y_{n}\right)=F(x, y) \\
& y=\lim _{n \rightarrow \infty} F\left(y_{n}, x_{n}\right)=F\left(\lim _{n \rightarrow \infty} y_{n}, \lim _{n \rightarrow \infty} x_{n}\right)=F(y, x)
\end{aligned}
$$

and this proves that $(\mathrm{x}, \mathrm{y})$ is a coupled fixed point of $F$.

In what follows, we prove that Theorem 3 is still valid for $F$ not necessarily continuous, assuming the following hypothesis hold,

if $\left(x_{n}\right)$ is a nondecreasing sequence with $x_{n} \rightarrow x$ then $x_{n} \leq x$, for all $n \in N$.

if $\left(y_{n}\right)$ is a nonincreasing sequence with $y_{n} \rightarrow y$ then $y_{n} \geq y$, for all $n \in N$. 
Theorem 4. If in Theorem 3 we substitute the continuity of $F$ by the condition above mentioned we also obtain the existence of a coupled fixed point of $F$.

Proof.Following the proof of Theorem 3 we only have to check that $(x, y)$ is a coupled fixed point of $F$.

In fact, since $\left(x_{n}\right)$ is nondecreasing sequence and $x_{n} \rightarrow x$ and $\left(y_{n}\right)$ is nonincreasing and $y_{n} \rightarrow y$, by our assumption, $x_{n} \leq x$ and $y_{n} \geq y$ for every $n \in N$.

Applying the contractive condition we have

$$
\begin{aligned}
d\left(F(x, y), F\left(x_{n}, y_{n}\right)\right) & \leq \beta\left(\max \left(d\left(x, x_{n}\right), d\left(y, y_{n}\right)\right)\right) \max \left(d\left(x, x_{n}\right), d\left(y, y_{n}\right)\right) \\
& \leq \max \left(d\left(x, x_{n}\right), d\left(y, y_{n}\right)\right) .
\end{aligned}
$$

On the other hand by triangular inequality and (20) we get

$$
\begin{aligned}
d(x, F(x, y)) & \leq d\left(x, x_{n+1}\right)+d\left(x_{n+1}, F(x, y)\right. \\
& =d\left(x, x_{n+1}\right)+d\left(F(x, y), F\left(x_{n}, y_{n}\right)\right) \\
& \leq d\left(x, x_{n+1}\right)+\max \left(d\left(x, x_{n}\right), d\left(y, y_{n}\right)\right)
\end{aligned}
$$

As $x_{n} \rightarrow x$ and $y_{n} \rightarrow y$ and taking $n \rightarrow \infty$ in the last inequality, we have

$$
d(x, F(x, y))=0
$$

and, consequently, $F(x, y)=x$.

Using a similar argument it can be proved that $y=F(y, x)$ and this finishes the proof.

In what follows, we give a sufficient condition for the uniqueness of coupled fixed point in Theorem 3 and Theorem 4 . This condition is

$$
\begin{aligned}
& \text { for }(x, y),(u, v) \in X \times X \text { there exists }(z, t) \in X \times X \\
& \text { which is comparable to }(x, y) \text { and }(u, v) .
\end{aligned}
$$

Notice that in $X \times X$ we consider the partial order relation given by

$$
(x, y) \leq(u, v) \Leftrightarrow x \leq u \quad \text { and } \quad y \geq v
$$


Theorem 5. Adding condition $(*)$ to the hypotheses of Theorem 3 (resp. Theorem 4) we obtain uniqueness of the coupled fixed point of $F$.

Proof.Suppose that $(x, y)$ and $(z, t)$ are coupled fixed point of $F$, that is $x=F(x, y)$, $y=F(y, x), z=F(z, t)$ and $t=F(t, z)$.

Let $(u, v)$ be an element of $X \times X$ and comparable to $(x, y)$ and $(z, t)$. Suppose that $(x, y) \geq(u, v)$ (the proof is similar in other cases).

We construct the sequences $\left(u_{n}\right)$ and $\left(v_{n}\right)$ defined by

$$
u_{0}=u, v_{0}=v, u_{n+1}=F\left(u_{n}, v_{n}\right), v_{n+1}=F\left(v_{n}, u_{n}\right) .
$$

We claim that $(x, y) \geq\left(u_{n}, v_{n}\right)$ for each $n \in N$.

In fact, we will use the mathematical induction.

For $n=0$, as $(x, y) \geq\left(u_{n}, v_{n}\right)$, this means $u_{0}=u \leq x$ and $y \geq v=v_{0}$ and, consequently, $\left(u_{0}, v_{0}\right) \leq(x, y)$.

Suppose that $(x, y) \geq\left(u_{n}, v_{n}\right)$, then using mixed monotone property of $F$, we get

$$
\begin{aligned}
& u_{n+1}=F\left(u_{n}, v_{n}\right) \leq F\left(x, v_{n}\right) \leq F(x, y)=x \\
& v_{n+1}=F\left(v_{n}, u_{n}\right) \geq F\left(y, u_{n}\right) \geq F(y, x)=y
\end{aligned}
$$

and this proves our claim.

Now, since $u_{n} \leq x$ and $v_{n} \geq y$, using the contractive condition we have

$$
\begin{aligned}
d\left(x, u_{n}\right) & =d\left(f(x, y), F\left(u_{n-1}, v_{n-1}\right)\right) \\
& \leq \beta\left(\max \left(d\left(x, u_{n-1}\right), d\left(y, v_{n-1}\right)\right)\right) \max \left(d\left(x, u_{n-1}\right), d\left(y, v_{n-1}\right)\right) \\
& \leq \max \left(d\left(x, u_{n-1}\right), d\left(y, v_{n-1}\right)\right),
\end{aligned}
$$

and, analogously

$$
\begin{aligned}
d\left(y, v_{n}\right) & =d\left(F(y, x), F\left(v_{n-1}, u_{n-1}\right)\right) \\
& =d\left(F\left(v_{n-1}, u_{n-1}\right), F(y, x)\right) \\
& \leq \beta\left(\max \left(d\left(x, u_{n-1}\right), d\left(y, v_{n-1}\right)\right)\right) \cdot \max \left(d\left(x, u_{n-1}\right), d\left(y, v_{n-1}\right)\right) \\
& \leq \max \left(d\left(x, u_{n-1}\right), d\left(y, v_{n-1}\right)\right) .
\end{aligned}
$$

From (22) and (23), we obtain

$$
\begin{aligned}
\max \left(d\left(x, u_{n}\right), d\left(y, v_{n}\right)\right) & \leq \beta\left(\max \left(d\left(x, u_{n-1}\right), d\left(y, v_{n-1}\right)\right)\right) \max \left(d\left(x, u_{n-1}\right), d\left(y, v_{n-1}\right)\right) \\
& \leq \max \left(d\left(x, u_{n-1}\right), d\left(y, v_{n-1}\right)\right) .
\end{aligned}
$$


This last inequality implies that

$$
\max \left(d\left(x, u_{n}\right), d\left(y, v_{n}\right)\right) \leq \max \left(d\left(x, u_{n-1}\right), d\left(y, v_{n-1}\right)\right),
$$

and, consequently, the sequence $\left(\max \left(d\left(x, u_{n}\right), d\left(y, v_{n}\right)\right)\right)$ is decreasing and nonnegative, and so,

$$
\lim _{n \rightarrow \infty}\left(\max \left(d\left(x, u_{n}\right), d\left(y, v_{n}\right)\right)\right)=r,
$$

for certain $r \geq 0$.

Now we show that $r=0$, on the contrary assume $r>0$.

Using (24) and letting $n \rightarrow \infty$ in (23) we have

$$
r \leq \beta(r) r,
$$

and consequently $\lim _{n \rightarrow \infty} \beta(r)=1$, since $\beta \in \delta$, then $\lim _{n \rightarrow \infty} \max \left(d\left(x, u_{n}\right), d\left(y, v_{n}\right)\right)=0$.

This contradiction, proves $r=0$, this gives us $u_{n} \rightarrow x$ and $v_{n} \rightarrow y$.

using a similar argument for $(z, t)$ we can obtain

$$
u_{n} \rightarrow z \text { and } v_{n} \rightarrow t
$$

and the uniqueness of limit gives $x=z$ and $y=t$.

This finishes the proof.

Theorem 6. Under assumption of Theorems 3 (or Theorem 4), suppose that $x_{0}$ and $y_{0}$ are comparable then the coupled fixed point $(x, y) \in X \times X$ satisfies $x=y$.

Proof. Assume $x_{0} \leq y_{0}$ (similar argument for $y_{0} \leq x_{0}$ ).

We claim that $x_{n} \leq y_{n}$ for all $n \in N$, where $x_{n+1}=F\left(x_{n}, y_{n}\right)$ and $y_{n+1}=F\left(y_{n}, x_{n}\right)$.

Obviously, the inequality is satisfied for $n=0$.

Suppose $x_{n} \leq y_{n}$.

Using the mixed monotone property of $F$, we have

$$
x_{n+1}=F\left(x_{n}, y_{n}\right) \leq F\left(y_{n}, y_{n}\right) \leq F\left(y_{n}, x_{n}\right)=y_{n+1}
$$

and this proves our claim.

Now, using the contractive condition, as $x_{n} \leq y_{n}$, we get

$$
\begin{aligned}
d\left(x_{n+1}, y_{n+1}\right) & =d\left(y_{n+1}, x_{n+1}\right)=d\left(F\left(y_{n}, x_{n}\right), F\left(x_{n}, y_{n}\right)\right) \\
& \leq \beta\left(d\left(x_{n}, y_{n}\right)\right) \max \left(x_{n}, y_{n}\right) \leq \max \left(x_{n}, y_{n}\right)
\end{aligned}
$$


then, we have

$$
d\left(x_{n+1}, y_{n+1}\right) \leq d\left(x_{n}, y_{n}\right) .
$$

Thus, $\lim _{n \rightarrow \infty} d\left(x_{n}, y_{n}\right)=r$, for certain $r \geq 0$.

Taking $n \rightarrow \infty$ in (25), we have

$$
r \leq \beta(r) . r \quad \text { or } \quad \beta(r)=1,
$$

since $\beta \in \delta$ then $\lim _{n \rightarrow \infty} d\left(x_{n}, y_{n}\right)=0$, this gives us $r=0$.

As $x_{n} \rightarrow x$ and $y_{n} \rightarrow y$ and $\lim _{n \rightarrow \infty} d\left(x_{n}, y_{n}\right)=0$, we have $0=\lim _{n \rightarrow \infty} d\left(x_{n}, y_{n}\right)=$ $d\left(\lim _{n \rightarrow \infty} x_{n}, \lim _{n \rightarrow \infty} y_{n}\right)=d(x, y)$ and thus $x=y$.

This finishes the proof.

\section{References}

[1] A. Amini-Harandi, H. Emami, A fixed point theorem for contraction type maps in partially ordered metric spaces and application to ordinary differential equations, Nonlinear Analysis. 72 (2010) 2238-2242.

[2] J. Harjani, B. Lpez, K. Sadarangani,Fixed point theorems for mixed monotone operators and applications to integral equations, Nonlinear Analysis. 74 (2011) 1749-1760.

[3] T.G. Bhaskar, V.Lakshmikantham, Fixed point theorems in partially ordered metric spaced and applications, Nonlinear Anal. 65(2006) 1379-1393.

[4] R.P. Argarwal, M.A. El-Gebeily, D. O'Regan, Generalized contraction in partially ordered metric spaces, Appl. Anal. 87 (2008) 109-116.

[5] Dz. burg, S. Kalabusic, M.R.S. Kulenovic, Global attractivity results for mixed monotone mappings in partially ordered complete metric spaces, Fixed Point Theory Appl.(2009).Article ID 762478.

[6] L. Ciric,N. Cakid,M.. Rajovic,J.S. Ume,Monotone generalized nonlinear contractions in partially ordered metric spaces, Fixed Ponit Theory Appl. (2008) Article ID 131294. 
[7] J. Harjani, K. Sadarangani,Fixed point theorems for weakly contractive mapings in partially ordered sets, Nonlinear Anal.71 (2009) 3403-3410.

[8] J. Harjani, K. Sadarangani,Generalized contraction in partially ordered metric spaces and applications to ordinary differential equations, Nonlinear Anal. 72 (2010) 1188-1197.

[9] J. Harjani, K. Sadarangani,Fixed Point Theorems for Mappings satisfying a condition of integral type in partially ordered set, Journal of Convex Analysis (in press).

[10] V. Lakshmikantham, L. Ciric, Coupled fixed point theorem for nonlinear contractions in partially ordered metric spaces, Nonlinear Anal. 70 (2009) 321-342.

[11] J.J. Nieto, R. Rodriguez-Lopez, Existence of extermal solutions for quaratic fuzzy equations, Fixed Point Theory Appl. (2005) 321-342.

[12] J.J. Nieto, R. Rodriguez-Lopez, Contractive mappings theorem in partially ordered sets and applications to ordinary differential equations, Order 22 (2005) 223-239.

[13] J.J. Nieto, R. Rodriguez-Lopez, Aplications of contractive-like mappiongs princples to fuzzy equations, Rev.Math.Complut. 19 (2006) 361-383.

[14] J.J. Nieto,R.L. Pouso, R. Rodriguez-Lopez, Fixed point theorems in ordered abstract spaces, Proc. Amer.Math. Soc., 135 (2007) 2505-2517.

[15] J.J. Nieto, R. Rodriguez-Lopez, Existence and uniqeness of fixed point in patially ordered sets and applications to ordinary differential equations, Acta Math. Sinica 23 (2007) 2205-2212.

[16] D.O'Regan, A. Petrusel, Fixed point theorems for generalized contraction in oerdered metric spaces, J.Math. Anal. Appl. 341 (2008)1241-1252.

[17] A. Petrusel, I.A.Rus, Fixed point theorems in ordered L-spaces, Proc. Amer. Math. Soc. 134 (2006)411-418.

[18] A.C.M. Ran, M.C.B. Reurings, A fixed point theorems in partially ordered sets and some applications to matrix equations, Proc. Amer. Math. Soc. 132 (2004) 1432-1443.

[19] Z. Drici, F.A. Mcrae, J.Vasundhara Devi, Fixed point theorems in partially ordered metric spaces for operators with PPF dependence, Nonlinear Anal. 7 (2007) 641-647. 
[20] Y. Wu, New fixed point theorems and applications of mixed monotone operator , J.Math. Anal. Appl. 341 (2008) 883-393.

[21] A. Cabada, J.J. Nieto, Fixed point and approximate solutions for nonlinear operator equations, J. Comput. Appl.Math. 113 (2000) 17-25.

[22] M.S. Khan, M. Swaleh, S. Sessa, Fixed point theorems by altering distanced between the points, Bull. Austral. Math. Soc. 30(1) (1984) 1-9.

[23] M. Geraghty, on contractive mappings, Proc. Amer. Math. Sox.40 (1973) 604-608.

[24] D. Guo, V, Lakshmikantham, Coupled fixed point of nonlinear operators with applicatons, Nonlinear Anal.11 (1987) 623-632.

[25] D. Guo, V, Lakshmikantham, Nonlinear Problems in Abstract Cones, Academic Press, New Yourk, 1988.

[26] D. Guo, Existence and uniqeness of positive fixed point for mixed montoneo perators with applications, Appl. Anal.46 (1992).

[27] Z.Zhang, New fixed point theorems of mixed montone operator and applications, J.Math.Anal.Appl.204 (1996), 307-319.

[28] S.S. Zhang, Y.H. Ma, Coupled fixed points for mixed montone condensing operators and an existense theorem of the soloution for a class of functional equation arising in dynamic programming, J.Math. Anal. Appl.160 (1991) 468-479.

[29] Y.Sun, A fixed point theorem for mixed monotone operator with applications, J.Math. Anal. Appl. 156 (1991) 240-252. 